\title{
Erratum to: Relapse to smoking during unaided cessation: clinical, cognitive and motivational predictors
}

\author{
Jane Powell • Lynne Dawkins • Robert West • \\ John Powell $\cdot$ Alan Pickering
}

Published online: 19 April 2011

(C) Springer-Verlag 2011

\section{Erratum to: Psychopharmacology \\ DOI 10.1007/s00213-010-1975-8}

We have discovered a directional coding error for the derived cue reactivity (CR) index. Thus contrary to the finding initially reported, $\mathrm{CR}$ during acute abstinence (baseline) was inversely associated with relapse risk: i.e., smokers showing high baseline CR were less likely to relapse at follow-up. In all other respects test values remain as stated. Logistic regression showed that pre-cessation salivary cotinine, itself the strongest unique predictor of relapse, explained the relationship with baseline CR. Some participants with high cotinine levels showed low baseline $\mathrm{CR}$ because their 'pre-cue craving' (prior to presentation of the smoking cue) was at ceiling. This potentially explains the negative relationship between CR and relapse, and so analyses were re-run for 7 day outcome excluding participants whose pre-cue craving was 6 or 7 (maximum).

The online version of the original article can be found at http://dx.doi. org/10.1007/s00213-010-1975-8.

J. Powell $(\triangle) \cdot$ A. Pickering

Department of Psychology, Goldsmiths University of London,

Lewisham Way, New Cross,

London SE14 6NW, UK

e-mail: j.powell@gold.ac.uk

L. Dawkins

School of Psychology, University of East London,

Romford Road, Stratford,

London E15 4LZ, UK

The remaining 57 successful abstainers did not differ from the remaining 57 relapsers in pre-cue craving $(3.18 \pm 1.35$ vs $3.23 \pm 1.20 ; \mathrm{t}=0.22, \mathrm{~ns})$; nevertheless there was a trend for them to show stronger $\mathrm{CR}(1.14 \pm 1.08$ vs $0.79 \pm 1.13 ; \mathrm{t}=1.7$, $p=0.09)$. The observed CR-relapse association therefore appears not to be an artifact of elevated pre-cue craving. An alternative, speculative, interpretation is premised on a putative association between higher smoking/cotinine levels and hypofunction of dopaminergic brain circuitry during acute nicotine deprivation. This circuitry is believed to mediate salience attribution; hence heavier smokers might show attenuated responsiveness to appetitive cues including those associated with smoking, whilst finding it harder to abstain because of their dependence on nicotine to normalise brain function.

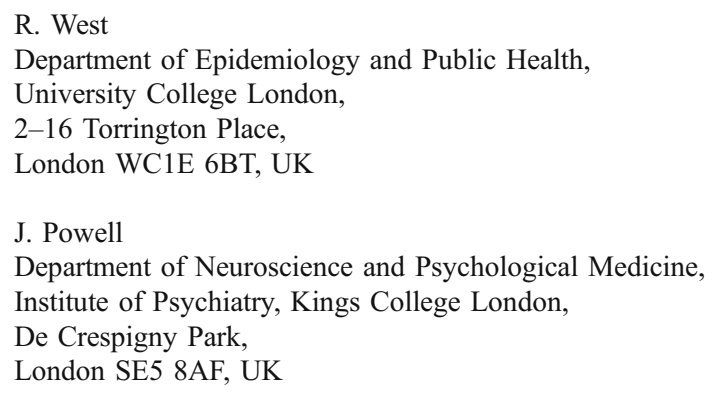

